\title{
A ERA DOS AVÓS CONTEMPORÂNEOS NA EDUCAÇÃO DOS NETOS E RELAÇÕES FAMILIARES: UM ESTUDO DE CASO NA UNIVERSIDADE DA MATURIDADE DA UNIVERSIDADE FEDERAL DO TOCANTINS
}

\author{
Neila Barbosa Osório ${ }^{1}$ \\ Luiz Sinésio Neto ${ }^{2}$ \\ Josafá Miranda de Souza ${ }^{3}$
}

\begin{abstract}
Resumo: Neste artigo, narramos as práticas educativas realizadas entre os avós do projeto UMA e seus netos. Será exposto como os avós acadêmicos compreendem essa nova realidade social que modifica o quadro familiar do século XXI. É uma pesquisa descritiva com abordagem qualitativa com a forma de Estudo de Caso e uma análise de conteúdo. Concluiu-se que é contemporâneo ser avô ativo, por isso, essa inovada função social deve ser estudada e refletida nas famílias entre todas as geraçóes para se evitarem conflitos intergeracionais.
\end{abstract}

Palavras-chave: Práticas educativas, avós e netos, conflito intergeracional.

\section{THE ERA OF CONTEMPORARY GRANDMOTHERS IN NETWORK EDUCATION AND FAMILY RELATIONS: A CASE STUDY IN THE UNIVERSITY OF MATURITY OF THE FEDERAL UNIVERSITY OF TOCANTINS}

\begin{abstract}
In this article we narrate the educational practices performed between the grandchildren and grandparents of UMA project and their grandchildren. It will be exposed how the academic grandparents understand the new social reality that modifies the family context of the 21 st century. It is a descriptive research with qualitative approach with the form of Case Study and a content
\end{abstract}

1 Docente do Programa de Mestrado em Educação e Coordenadora Nacional da UMA da Universidade Federal do Tocantins.

2 Docente do Programa de Mestrado em Ensino em Ciências e Saúde e Coordenador Nacional da UMA da Universidade Federal do Tocantins.

3 Mestrando do Programa de Mestrado em Educação e docente da UMA da Universidade Federal do Tocantins. 
analysis. It was concluded that it is contemporary to be an active grandparent so this innovative social function must be studied and reflected in families among all generations to avoid intergenerational conflicts.

Keywords: educational practices; grandparents and grandchildren; intergenerational conflicts.

\section{INTRODUÇÃO}

O papel dos avós no mundo contemporâneo tem sido alvo de estudos (OSORIO, 2008). Interessantemente, somente os seres humanos possuem este vínculo familiar; os animais não conhecem seus avós. Após o período de procriação, as vidas destes seres não possuem nenhum significado para as gerações seguintes, e passam a ser um problema na disputa por alimentação e espaço.

Para eles, as relações intergeracionais não são necessárias: tudo de que precisam está codificado em seu material genético. Os humanos trazem uma história diferente. Sua capacidade de sobrevivência depende da interdisciplinaridade cultural, ou seja, de influência mútua entre as culturas, não do gene. Com isso, passa a ser uma conquista que os adultos vivam tempo suficiente para oferecer informações de uma geração a outra.

Até há pouco tempo, os avós não existiam: em meados do século XIX, só $3 \%$ da população humana ultrapassava os 60 anos. Hoje, o cenário é outro: muitos avós conhecem seus netos até esses se tornarem adultos. E é cada vez mais natural as crianças conhecerem seus quatro antepassados ao longo de sua vida.

Como envelhecer é a máxima novidade desse século, ser avós mais ainda, estes não possuem papel determinante. Não é complicado compreender esse novo status. Tudo vai depender do significado que cada um dá a esse momento da vida. Por isso, decidimos estudar esse fenômeno que implica todas as sociedades. E nós, pesquisadores da área de Envelhecimento Humano, partimos para estudar práticas educativas inovadoras intergeracionais.

No percorrer dessa caminhada, destacamos uma passagem relevante para a ciência deste assunto: as escolas de educação infantil começaram a apresentar interesse em aproximar os avós para resgatarem as famílias das crianças. Fazê-las apreciarem suas origens. São histórias de coragem e vivência que dão base para as crianças se sentirem mais fortes diante da vida e isso é essencial para nossos estudos.

O fortalecimento de pesquisas com acadêmicos de graduação dentro das escolas públicas resultou em uma publicação sobre esse assunto considerado pouco desvelado na educação. Ao crer que a saída do envelhecer digno e ativo esteja numa saudável relação intergeracional. Foi desenvolvida a obra intitulada: "Avós e netos: uma relação de afetos e desafios", em 2012, pela editora Biblos, onde foi traçado um esboço dessa relação afetiva intergeracional permeada de afeto e desafios pela ausência de compreensão dos sentimentos das diferentes gerações no cotidiano. O embasamento teórico deste artigo está fundamentado nessa publicação e nas experiências com crianças, adultos e velhos dos autores desse estudo, desde 1998. 
Neste artigo, iremos narrar as práticas educativas realizadas entre os avós do projeto Universidade da Maturidade (UMA) e seus netos. Será exposto como os avós-acadêmicos compreendem essa nova realidade social que modifica o quadro familiar há séculos formalizado.

\section{Caminhos percorridos: Estudo de caso: os acadêmicos-avós da Universidade da Maturidade da Universidade Federal do Tocantins}

Este artigo é uma pesquisa descritiva com abordagem qualitativa com a forma de Estudo de Caso e uma análise de conteúdo. Serão apresentadas Práticas educativas entre avós e netos e seus conflitos intergeracionais dentro do projeto de extensão da Universidade da Maturidade da Universidade Federal do Tocantins. Utilizou-se a entrevista semiestruturada, observação participativa, diário de campo e as análises foram de conteúdo. Participaram deste estudo 30 acadêmicos do projeto de extensão da UMA entre 50 a 80 anos, sendo 20 mulheres e 10 homens. Evidenciou-se um cenário complicado e multifacetado que mereceu atenção e análise cuidadosa, e que objetivou compreender essa realidade na vida dos acadêmicos-avós.

Inicialmente, indagou-se sobre a intensidade da missão deles como avós: $70 \%$ disseram que tiveram seus papéis expandidos, os netos foram morar com eles, que obtiveram a custódia legal e assumiram os cuidados diários, além de responsabilizarem-se financeiramente por aqueles. Somente $30 \%$ disseram que continuam exclusivamente avós, sem nenhum compromisso de responsabilidade integral.

A segunda questão foi sobre a estrutura familiar desses sujeitos, e se constataram dois modelos distintos. No primeiro, descobriram-se os lares compostos por três gerações (que tiveram considerável aumento a partir da década de 1980), em que os pais ou ao menos um deles reside com avós e netos.

O segundo modelo evidenciado foi o dos pais ausentes do lar, coube aos avós completo cuidado dos netos. Houve relatos de acontecimentos em que se evidenciaram conflitos entre avós e pais quanto à educação das crianças ou de descompromisso por parte dos pais e perda de privacidade. Tais situações e perdas também aumentaram consideravelmente a depressão destes avós. Nas famílias pesquisadas em que ambos os pais estão ausentes de casa e somente os avós são responsáveis pelos netos, esses passam a ocupar a função de pais suplentes.

Compararam-se os dois tipos de composições familiares. Apesar de ambas as situações gerarem stress, verificaram-se vestígios de que os avós que vivem em famílias com o segundo tipo de arranjo descrito são mais sobrecarregados, estão mais contidos a isolamento social e desgaste emocional.

A substituição de papéis assumidos pelos avós da UMA/UFT em relação a seus netos ultrapassou os limites de funcionalidade, porque, segundo eles, seus netos os chamam carinhosamente de mãe e pai, ou afirmam que têm duas mães e dois pais quando o cuidado é dividido entre as partes. 
$\mathrm{Na}$ terceira pergunta, apresentou-se uma escala de valores da vida moderna para avaliarem o que mais pesava em sua missão de pais substitutos: $30 \%$ justificaram que o desemprego de seus filhos gera a necessidade de ajuda financeira por parte deles, avós; $40 \%$ alegaram o divórcio do casal, com retorno do filho para a casa dos pais, juntamente com os netos; $10 \%$ disseram que houve novo casamento de pais separados e a não aceitação das crianças por parte do cônjuge; $10 \%$ gravidez precoce e despreparo para cuidar dos filhos; $10 \%$ responderam morte precoce dos pais devido a violência ou doenças como a Síndrome da Imunodeficiência adquirida (AIDS); $10 \%$ justificaram a incapacidade dos pais decorrente de desordens emocionais ou neurológicas, uso de drogas, envolvimento em situações ilícitas e/ ou problemas judiciais.

Essa realidade de crianças sob a responsabilidade dos avós é reproduzida no Brasil, sabe-se que $20 \%$ dos domicílios brasileiros tinham velhos como chefes de família, o que expressa um número de mais de 8 milhões de lares. Deste total, $36 \%$ eram compostos por casal com filhos e/ou outros parentes (INSTITUTO BRASILEIRO DE GEOGRAFIA E ESTATÍSTICA, 2002). Esse fato pode indicar uma probabilidade maior de haver netos que residem com os avós e sob a responsabilidade deles.

Ter avós como mentores ou tutores pode ser benéfico para as crianças, principalmente porque poderão usufruir uma sensação de pertencimento à sua família de origem, especialmente na ausência dos pais. Contudo, dificuldades emocionais para as crianças também podem resultar dessa situação. Para os avós não é diferente, trazem benfeitorias e dificuldades relacionadas a esse compromisso.

A quarta pergunta foi sobre as consequências na vida deles, de assumirem essa função de pais-avós. Os entrevistados relataram aumento no sentimento de autoestima, sensações elevadas de moral e felicidade por exercerem um papel crucial para que as crianças não fossem levadas para casas estranhas ou instituições de adoção e mantivessem um senso de segurança e continuidade familiar. Enfatizaram cansaço, problemas de saúde e rupturas em suas vidas social e financeira.

Segundo Glass Junior e Huneycutt (2002), as mudanças decorrentes de assumir a função parental na idade avançada são mais dramáticas que em outro momento da vida. Os velhos já não têm a mesma energia para cuidar de crianças, sendo usualmente mais vitimados por fragilidades físicas e de saúde geral.

Uma parte dos acadêmicos da UMA/UFT ocupa-se do cuidado dos netos, de seus pais ou sogros, sendo alvo de uma sobrecarga de tarefas e responsabilidades. Como perdas mais relevantes decorrentes da situação, os participantes do estudo citam planos futuros que envolviam a vida social culturalmente esperada para a velhice, atividades de lazer e independência ocorrida da saída dos filhos de casa.

Além desses fatores, baixa saúde percebida e queda no status financeiro também são perdas consideráveis. A vida social deles foi alterada e há um sentimento de estar deslocado, porque os avós não têm tempo para interagir com os amigos de sua idade e os pais dos colegas de seus netos lhes parecem diferentes e distantes. Muitos se envergonham e têm sua autoestima afetada porque seus filhos não foram 
capazes de cuidar dos próprios filhos, o que pode ainda causar ressentimentos para com aqueles.

A quinta pergunta investiga por que existem efeitos negativos em relação ao cuidado dos netos sobre os avós. A maioria afirma que essa experiência é gratificante, já que apresenta uma renovação de suas metas e certa movimentação para suas vidas, além de novos padrões de interação social. Apesar de dispuserem de menos tempo para atividades de lazer, eles encontram novas oportunidades de envolvimento, podem evitar a solidão e o isolamento que às vezes os acometem. A tendência de terem suas vidas sociais afetadas de várias formas, muitos avós defenderam a ideia de que ter alguém em casa equilibra as demais perdas.

Os avós entrevistados mencionaram determinadas dificuldades, mas a maioria se fixou principalmente aos benefícios e felicidades advindos do cuidar dos netos, aborda a luta para confrontar os percalços e dificuldades com relações cultivadas pelo afeto.

Foram relatados, pelos avós, sentimentos de solidão e tristeza provenientes dos momentos em que os netos não estão em sua companhia, lembram-se da satisfação em tê-los por perto. Um momento de frustração descrito pelos avós acontece quando, devido às dificuldades financeiras, eles não podem dar aos netos o que pedem e há, ainda, certo receio de não conseguirem proporcionar-lhes tudo o que precisam. Mas as frustrações e dificuldades parecem pequenas quando se sentem preencher por certa leveza diante da vida que as crianças lhes apresentam e os ensinam a sentir e aproveitar.

A sexta pergunta foi sobre a saúde para aqueles que assumem o papel de avós-cuidadores. Eles disseram que ficaram mais predispostos à baixa satisfação com sua saúde, o que indica que decai saúde percebida perante os que os nãocuidadores. Para os autores, os resultados relativos à satisfação com a saúde e saúde percebida podem estar associados com depressão e/ou maior consciência de suas limitações funcionais.

Para Kropf e Burnette (2003), os avós que cuidam dos netos estão mais sujeitos a apresentar problemas funcionais e de saúde, possuem mais chances de apresentar sintomas depressivos e têm dificuldades para manter contato com a rede social de amigos. Em contrapartida, esses avós relatam consistentemente benefícios trazidos pela experiência de cuidar, como alegria e significado para suas vidas, proporcionando-lhes companhia e maior propósito social.

A sexta pergunta questionou sobre os motivos que levaram os acadêmicosavós da UMA/UFT a assumirem o papel de avós-país de seus netos. Responderam que não foi fácil ou confortável e que um dos fatores vitais para dizerem sim foram as perspectivas sociais para que os avós acolham seus netos. Afirmaram que vivem numa sociedade que valoriza laços e responsabilidades familiares, de modo que pode parecer desumano ou insensível eles deixarem de cuidar de seu neto - "sangue de seu sangue" - caso ele precise. Mas possivelmente não é só a sociedade que os conduz a assumirem esse compromisso; os próprios sentimentos que nutrem pelos netos os fazem. 
Entretanto, a minoria dos entrevistados disse não aos filhos quando estes lhes pediram para ajudarem a cuidar das crianças. Responderam que não querem ser "avós de profissão" ou "avós de tempo integral”, pois julgam essas hierarquias como faces negativas do papel de avós e não pretendem assumi-las. Uma das entrevistadas disse haver um espaço da velhice em que os velhos sentem uma necessidade muito grande de aproveitar cada hora, cada minuto.

Essa pequena representação de acadêmicos-avós da UMA/UFT acredita que criou seus filhos e agora tem o direito de ir em busca de outros interesses, sente-se em um outro momento da vida e não deseja assumir tal obrigação.

Sobre o assunto, Debert e Simões (1998) definem a criação dessa etapa da vida pela sociedade como uma forma de negar o envelhecimento, alterarem-se os anos iniciais da velhice num período caracterizado como o momento de voltar-se para o lazer, para inovações e aprendizados e para a concretização de sonhos e planos que as cobranças da vida adulta não permitiram realizar. Assim, os velhos acabam por adotar um estilo de vida em que não cabe cuidar dos netos como babás ou cuidadores principais.

Percebeu-se, então, a presença de posições caracterizadas quanto ao cuidado dos netos. Há avós que não pestanejam ao aceitar o cuidado dos netos para si, cientes ou não das possíveis limitações a serem enfrentadas. Mas há também avós que não hesitam ao dizer não para esse tipo de apelo. De acordo com a avaliação dos pesquisadores, o que determinou esta concepção de valores foi o nível educacional e a classe socioeconômica dos avós. Os avós com melhor nível socioeconômico têm maior possibilidade de acessar as oportunidades que o mercado lhes oferece para viverem uma velhice classificada como ativa, recheada por viagens, atividades variadas e busca pelo rejuvenescimento (GLASS JUNIOR; HUNEYCUTT, 2002). As decisões destes velhos refletem posições que não devem ser julgadas, mas compreendidas como exemplos da heterogeneidade que caracteriza a experiência de envelhecer e de posicionar-se nas relações familiares dentro da UMA/UFT.

\section{Reflexóes educacionais sobre a UMA}

Adicionamos algumas reflexões sobre a UMA por compreender a necessidade de maior clareza sobre o local do estudo. Reflexões educacionais referem-se às perspectivas do projeto acerca da educação para velhos.

Existe um velho ditado que diz: papagaio velho não fala. E isso se aplica dentro da nossa sociedade para as pessoas que completam 40 anos em diante. Uma cultura onde a juventude virou um estilo de vida pensar em voltar a estudar é um paradigma.

Acontece que a vida é movimento, por isso os valores e conhecimentos de um dia atrás podem se tornar obsoleto hoje. Imagine uma pessoa de 40 anos uns 20 anos atrás: não possuía um dente na boca e já estava na antecâmara da morte. Hoje, aos 40 anos, ainda nem encontramos nosso primeiro amor e nem descobrimos nossa verdadeira vocação. 
Portanto, inserir os maduros dentro da universidade para uma formação gerontológica é fundamental para sua saúde mental e social. São práticas necessárias para fortalecer suas relações intergeracionais e evitarem conflitos.

Essa foi a nossa intenção ao construirmos a proposta do desenho Universidade da Maturidade da Universidade Federal do Tocantins (UMA/UFT) desde sua idealização. Ao avaliar a literatura, nota-se que em regra a temática velhice é pautada na pobreza, violência ou saúde. Porém, as repercussões do processo de envelhecimento populacional devem ser analisadas de forma mais ampla e integrada. A educação na maturidade encontra-se em plano secundário nas agendas públicas e científicas. Nesse sentido, a Universidade da Maturidade (UMA/UFT) contemporiza o debate sobre a educação para os maduros. Esse subitem atribui problematizações sobre a educação na velhice com a práxis no projeto UMA/UFT.

Essa proposta específica para os maduros é reforçada na fala de Escarbajal (2009) que ressalta ser um lamentável erro considerar a educação de velhos nas mesmas perspectivas utilizadas em outras etapas da vida. Por isso, a gerontogogia tem como finalidade central promover uma educação capaz de abranger aspectos afetivos, cognitivo e ao bem-estar social dos velhos, amplia, portanto, o significado do envelhecimento e a identidade humana.

O projeto UMA/UFT possui sede própria com uma infraestrutura composta por auditório, salas de formação, secretarias, laboratório de novas tecnologias, copa entre outros ambientes educacionais e administrativos, exclusivamente para o desenvolvimento do projeto.

Esse ambiente educacional além da estrutura material de qualidade também possui o componente afetivo; para os velhos, a sede é considerada deles "segunda casa”. Segundo Osório (2009) o espaço se tornou um ambiente intergeracional, pois acadêmicos dos diversos cursos de graduação e pós-graduação realizam projetos de extensão e pesquisas; para vários, a sede é "UMA casa de Avós".

Portanto, notadamente que o debate sobre o tema é de grande extensão. Ao mesmo tempo em que o velho é ainda novo na educação, o envelhecimento populacional e as mudanças rápidas do mundo contemporâneo tornam o avanço deste campo de estudo cada vez mais necessário.

Nossas experiências no trabalho educativo com os velhos, há 11 anos na UMA/UFT, atestam a eficiência de como a educação pode produzir novas imagens e novos saberes em relação aos velhos. Educação na Velhice? Sim.

Vamos sobressair três questões adjuvantes que são: princípios metodológicos ou a "gerontogogia", corpo docente qualificado e ambiente educacional.

A gerontologia, enquanto ciência, investiga e produz suporte às necessidades, potencialidades e ações que derivam da longevidade com possíveis implicações educacionais envolvidas (BOTH, 2001).

A UMA/UFT possui um currículo desenvolvido que estimula a reflexão do indivíduo sobre a expectativa do seu envelhecimento e dessa maneira determina a sua motivação para as ações educacionais. Isso explica a vontade dos velhos em não 
perderem o vínculo com o projeto, frases como "Eu não saio mais daqui até o fim dos meus dias" são comuns nas falas dos acadêmicos.

Outro fator importante a ser debatido na educação na velhice é a prática docente. De acordo com Cachioni (2015) no Brasil, raras são as referências ao docente. Não possuímos uma área definida para a sua formação. Ainda há questões que se encontram sem respostas, tais como: Que tipo de formação está sendo oferecida? Em que suportes teóricos e metodológicos se apoia essa formação? Destacamos a necessidade de intercâmbio científico com outros países que possuem vasta experiência, tais como, França, Bélgica, Suíça, Portugal e Holanda. $\mathrm{Na}$ experiência da UMA/UFT salientamos o grupo de pesquisa Pro-Gero Envelhecimento Humano, que possui pesquisadores a atuar na linha de pesquisa e formação de professores e processos de aprendizagem na velhice. No Programa de Pós-Graduação Mestrado em Educação é desenvolvida a disciplina "Tópicos especiais em Educação intergeracional", especialmente nesse ano um mestrando do programa realiza um intercâmbio em Portugal. Além da Pós-Graduação Latu Sensu em Gerontologia iniciada desde 2005.

O termo ambiente educacional, utilizado nesse editorial, refere-se ao conjunto de elementos, de ordem material ou afetiva, que circunda o educando, que nele deve necessariamente se inserir e que o inclui, quando vivencia os processos de ensino e aprendizado, e que exerce influência definida sobre a qualidade do ensino e a eficácia do aprendizado. Nesse sentido, Both (2001) destaca que esse espaço é uma forma de promover uma educação para o envelhecimento por meio do oferecimento e efetivação institucional para atender às reivindicações da população velha.

\section{Consideraçóes finais}

Envelhecer e ser avô no século XXI é o maior desafio desses avós. Porque nasceram no fogo a lenha e agora vivem o fast food, o mundo transformou rapidamente como nunca aconteceu e eles necessitam colaborar na educação dos netos.

Dentre os principais achados nessa pesquisa, a educação pode trazer para a relação avô-neto um elemento ímpar: avós representarem o passado que a criança não viveu, a experiência de vida. Esta interação intergeracional pode ajustar na formação integral do neto, principalmente nos aspectos cultural, psíquico evolutivo e formativo.

Educativamente, a convivência estimula a criatividade, memória, linguagem, o desenvolvimento psicológico infantil dentre outros e se aperfeiçoa na apropriação de um legado que é transmitido diariamente.

Esta troca cultural pode ser ao mesmo tempo afetiva entre o avô e o neto que, além de instigar a potencialidade intelectual e relacional de ambos, favorece a conservação da memória histórica, permite a redescoberta de uma presença ativa do velho na família. 
No aspecto psíquico evolutivo, o avô defende na estrutura do "Eu" enquanto dá suporte aos inúmeros processos projetivos, de autonomia, perdas, separações e luto. Os avós representam o elemento mediador na relação neto-filho, pois se desenvolve uma função mediadora nos diversos episódios e revoltas instintivas das crianças para com os pais.

Formativamente, o avô subsidia no entendimento das concepções sobre vida e morte, no afeto pelo próximo, no amor-próprio de suas origens. Esta percepção positiva da vida adquirida na infância poderá influenciar beneficamente seu comportamento nas idades seguintes.

Há poucas referências na literatura nacional sobre a mudança de papéis dos avós. A maioria dos dados e informações pesquisadas faz parte do cenário internacional. Apesar de viver-se uma realidade diferente no Brasil, tais estudos podem contribuir para elucidar o quadro em que os avós, porque lutam por uma sociedade que ofereça oportunidade para todas as idades, encontram-se envolvidos no cuidado de seus netos, seja dividindo as responsabilidades com os pais das crianças ou ocupando-se integralmente desse compromisso.

$\mathrm{O}$ interesse por pesquisas sobre o assunto foi incentivado sobretudo pelo número crescente de avós na UMA que vivenciam essa situação, que muitas vezes se concordou como especial. Por isso os pesquisadores quiseram conhecer os efeitos dessa nova condição familiar sobre a vida dos seus acadêmicos-avós.

Há alguns anos os antepassados cuidavam dos netos na maioria das vezes de maneira esporádica e casual. Atualmente, e com certa frequência, verificou-se que a grande maioria dos entrevistados ajuda os filhos a cuidar das crianças, ou ainda histórias de avós que se tornam cuidadores integrais e até legais dos netos, ocupam um papel de pais substitutos.

Verificaram-se, após assumirem a tutoria dos netos, os efeitos negativos sobre diversos âmbitos da vida dos avós, tais como sobrecarga financeira, conflitos com filhos pela educação das crianças e, às vezes, pela custódia legal dos netos, queda na qualidade da saúde física e emocional com incidência de depressão e baixa saúde percebida, interferência na vida social e familiar, cansaço e esgotamento emocional.

Todavia, esses avós não deixam de ressaltar que também são afetados por efeitos positivos, dentre os quais um senso de renovação pessoal e de dever cumprido ao oferecerem a seus netos a oportunidade de terem uma família; a chance de terem companhia e se livrarem do sentimento de solidão e a gratificação por fornecerem uma nova geração com cuidados e ensinamentos; o que reflete a geratividade - característica comum a esse período de vida.

Assim, essa situação - ser mãe/pai de crianças e/ou adolescentes novamente - muitas vezes inesperada, nesse momento de suas vidas, teve impactos sobre a saúde física e emocional desses avós, afeta sua qualidade de vida. Contudo, as relações com os netos envolveram também sentimentos, senso de obrigação familiar e satisfações que em muitos casos sobrepuseram-se ao ônus que o cuidar dos netos poderia acarretar. 
Compreender essa nova configuração familiar em que muitos avós estão inseridos é tarefa para os profissionais preocupados com o bem-estar dos envolvidos nessa relação e em especial dos familiares que precisam adquirir conhecimentos desse ciclo de vida que começa a tomar uma dimensão imponente, irreversível e mundial.

Concluiu-se que as práticas educativas realizadas entre os avós do nosso projeto UMA e seus netos são uma referência dentro das políticas sociais. É um caminhar educativo extenso permeado de afetividade para os avós acadêmicos compreendem essa nova realidade social que modifica o quadro familiar do século XXI. Concluiu-se, ainda, que é contemporâneo ser avô ativo, por isso essa inovada função social deve ser estudada e refletida nas famílias entre todas as gerações para se evitarem conflitos intergeracionais. Por isso a Universidade de Maturidade se propõe a levar adiante.

\section{Referências}

BOTH, A. Educação Gerontológica: posições e proposições. Erechim: Ed. São Cristóvão, 2001.

CACHIONI, M. Metodologias e estratégias pedagógicas utilizadas por educadores de uma Universidade Aberta à Terceira Idade. Educação \& Realidade, v. 40, n. 1, 2015.

ESCARBAJAL, A.H. Personas Mayores, Educación y Emancipación. In: ÓPEZ, M.M, ESCARBAJAL, A.H. Alternativas Socioeducativas para las Personas Mayores. Madrid: Dykinson, 2009.

DEBERT, G. G.; SIMÕES, J. A. A aposentadoria e a invenção da "terceira idade". In:

DEBERT, G. G. (Org.). Antropologia e velhice. 2. ed. Campinas: IFCH/Unicom, 1998. p. 29-44. (Texts Didactics, n. 13).

DELLMANN-JENKINS, M.; BLANEMEYER, M.; OLESH, M. Adults in expander grandparent's roles: considerations for practice, policy, and research. Educational Gerontology, Abingdon, Oxon v. 28, p. 219-235, 2002.

DREW, L. M.; SMITH, P. K. Implications for grandparents when they lose contact with their grandchildren: divorce, family feud and geographical separation. Journal of Mental Health Aging, Baltimore, v. eight, n. 2, p. 95-119, 2002.

GLASS JUNIOR, J. C.; HUNEYCUTT, T. L. Grandparent's parenting grandchildren: extent of situation, issues involved, and educational implications. Educational Gerontology, Abingdon, Oxon, v. 28, p. 139-161, 2002.

GOODMAN, C.; SILVERSTEIN, M. Grandmothers raising grandchildren: family structure and well-being in culturally diverse families. The Gerontologist, Washington, D.C v. 42, n. 5, p. 676-689, out. 2002. 
GUSMÃO, N. M. M. de. Infância e velhice: desafios da multicultural idade. In:

(Org.). Infância e velhice: pesquisa de ideias. Campinas: Alínea, 2003. cap. 1, p. 15-32.

INSTITUTO BRASILEIRO DE GEOGRAFIA E ESTATÍSTICA. Perfil dos velhos responsáveis pelos domicílios no Brasil 2000. Estudos e Pesquisas: Informação Demográfica e Socioeconômica, Rio de Janeiro n. 9, 2002. Disponível em: <http://www. ibge.gov.br>. Acesso em: 20 de outubro de. 2017.

KROPF, N. P.; BURNETTE, D. Transparentes as Family careies: lesos for intergenerational education. Educational Gerontology, v. 29, p. 361-372, 2003.

MINKLER, M.; FULLER-THOMPON, E. The health of grandparents raising grandchildren: results of a national study. American Journal of Public Health, Washington, DC, v. 89, n. 9, p. 1.384-1.389, set. 1999.

OSÓRIO, N. B; ANDRADE, C. M.; SILVA NETO L. S. Avô - Neto: uma relação de risco e afeto. Santa Maria: Biblos, 2008. 164 p. (Coleção Maturidade)

OSÓRIO, N.B; SILVA NETO, L.S. Interdisciplinaridade na terceira idade: o caso dos avós. São Paulo: Xamã, 2009.

OLIVEIRA, P. de S. Vidas compartilhadas: cultura e co-educação de gerações na vida cotidiana. São Paulo: Hucitec: Fapesp, 1999. p. 32-40. (Coleção Linguagem e Cultura).

PARK, M. B. O ciclo de vida representado nas páginas dos almanaques de farmácia brasileiros. In: VON SIMSON, O. R. de M.; NERI, A. L.; CACHIONI, M. (Org.). As múltiplas faces da velhice no Brasil. Campinas: Átomo\&Alínea, 2004. cap. 2, p. 55-75.

REITZES, D. C.; MUTRAN, E. J. Grandparenthood: factor-influencing frequency of grandparent-grandchildren contact and grandparent role satisfaction. Journals of Gerontology: Social Sciences, v. 59 B, n. 1, p. S-9-S16, Jan. 2004.

SANTOS, S. M. A. dos. Infância e velhice: o convívio que nos abre caminhos. In: GUSMÃO, N. M. M. (Org.). Infância e velhice: pesquisa de ideias. Campinas: Alínea, 2003. cap. 3, p. 47-56.

SOMMERHALDER, C.; NOGUEIRA, E. J. As relações entre gerações. In: FREIRE, S. A.; NERI, A. L. (Org.). E por falar em boa velhice. Campinas: Papirus, 2000. cap. 7, p. 101-112. (Coleção Viva Idade). 